\title{
NOTAS SOBRE UM CURSO DE LITERATURA BRASILEIRA PARA ESTRANGEIROS NO BRASIL
}

\author{
Ana Amália Alves da Silva
}

\begin{abstract}
RESUMO
Neste artigo, apresento algumas reflexões sobre a criação do curso de Literatura Brasileira para Estrangeiros e da condução das aulas, na cidade de São Paulo, de maio a julho de 2015, como professora autônoma em uma escola de idiomas. Trata-se de um estudo de caso e de uma tentativa de contribuir para o entendimento da prática ainda jovem do ensino de Literatura Brasileira para falantes de outras línguas no Brasil.
\end{abstract}

PALAVRAS-CHAVE: ensino; literatura brasileira; PBLE.

\section{Introdução}

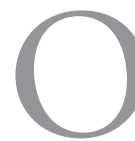

ensino da Literatura Brasileira para alunos estrangeiros, embora possa ser uma prática frequente em cursos de graduação no exterior em que o Português e/ou o Brasil sejam o objeto de estudo ${ }^{1}$, está ainda em seus primeiros passos dentro do território em nosso país. No Brasil, os poucos cursos de Literatura Brasileira para falantes de outras línguas começam a surgir no ensino do português como língua estrangeira. Ou seja, são em cursos de língua estrangeira que se darão os poucos, mas já interessantes casos de formação de turmas de literatura brasileira. Isso, em si, já possui uma certa particularidade.

Como sabemos, nossos cursos de graduação e pós-graduação mantêm as disciplinas de linguística em uma área de estudos, enquanto em outra estão as

1 Ver MONTEIRO, P. M. (Org.). A primeira aula: trânsitos da literatura brasileira no estrangeiro [recurso eletrônico]. São Paulo: Itaú Cultural, 2014. 
disciplinas de literatura. As pesquisas acadêmicas se dão, assim, em duas áreas distintas, mesmo que sejam ambas frentes de uma área maior, a de Letras. $\mathrm{O}$ ensino do português como língua estrangeira, uma frente jovem da linguística no Brasil, começa a apresentar a abertura para o diálogo com a literatura, sendo os profissionais da área que criam e conduzem cursos de literatura brasileira para seus alunos estrangeiros.

Esses profissionais, ainda, são poucos. No ambiente acadêmico, sabemos do caso da USP, que oferece, dentro do curso de português para estrangeiros do Centro de Línguas da FFLCH, os módulos de "Aspectos da cultura brasileira através de leituras, músicas e filmes", para o nível intermediário, e "Leitura e estudo de obras clássicas da literatura brasileira e/ou cultura brasileira”, para o nível avançado; do caso da UFRGS que oferece os módulos "Contos e crônicas", "Literatura Brasileira I" e "Literatura Brasileira II" no Programa de Português para Estrangeiros (PPE); e também da existência de um curso de Literatura Brasileira passado na $\mathrm{UFF}^{2}$. Fora do ambiente acadêmico, apesar de incessante busca, nada pudemos encontrar além do nosso até o momento. Digo fora do ambiente acadêmico porque, por mais que eu, como criadora do curso e professora das aulas, venha deste contexto, o curso que apresento aqui foi realizado em um ambiente privado de uma escola de idiomas de São Paulo, especializada em português para estrangeiros e francês para brasileiros, de nome Instituto aprenda ${ }^{2}$, onde todos os professores atuam como autônomos.

As formas adaptativas do ensino de língua estrangeira, bem como as novas formas criadas nos contextos das escolas de idiomas, precisam de maiores entendimentos por parte da academia. Este contexto precisa ser citado para podermos entender a dificuldade da existência dos cursos de literatura fora da academia e também para podermos compreender como este que descrevo pode ter tido o espaço para existir.

Neste artigo, faremos um breve comentário sobre a origem do curso, as consideraçôes de publicaçooes acadêmicas já existentes sobre o ensino de literatura no contexto PLE, para, então, podermos discutir algumas reflexóes originadas em sala de aula.

2 Do qual pouco sabemos, mas sua existência foi indicada no seguinte levantamento conduzido pela Profa. Dra. Matilde V. R. Scaramucci (Unicamp): http://www.unicamp. br/ $\sim$ matilde/portl2bra2006.html 


\section{Surgimento e configuração do curso de Literatura Brasileira para Estrangeiros (ou "Literatura Brasileira em 10 Passos")}

Como professora de língua estrangeira, foi na aprenda2 que despejei minhas maiores energias até o momento e é, portanto, onde mantive a experiência de trabalho mais longa (a rotatividade dos profissionais merece especial atenção). Isso porque, além do diploma em Letras contar no momento da seleçâo dos professores (o que não é sempre o caso na realidade do ensino privado de línguas), os professores são livres para criar materiais, propor mudanças e conduzir sequências de atividades diferentes de acordo com as necessidades e os interesses de cada curso que conduzem, o que, como sabemos, exige certa experiência e uma formaçâo sólida. É também um dos poucos centros que já consegue formar grupos de até oito estrangeiros para terem aulas de 4 horas, quatro vezes por semana, ao longo de cinco semanas consecutivas em Sáo Paulo (a maioria vai, normalmente, enviar os professores às casas ou empresas dos alunos, e as aulas seráo individuais). A chance de estar mais próxima à realidade de um ambiente escolar e de ter o espaço para a minha liberdade criadora foi o que mais me motivou a selecionar este espaço para tornar real o curso de Literatura Brasileira para Estrangeiros.

Nosso grupo de professores de português tem, na maioria, o diploma em Letras, ou licenciatura em Artes ou Ciências Sociais. Isso significa que muitas questôes educacionais, linguísticas e culturais são colocadas em prática e questionadas na prática individual de cada professor que compartilha este espaço. Ou seja, trata-se de um ambiente profissional alternativo onde professores como eu, que se encontram entre o mestrado e o doutorado, ou que náo podem contar com a bolsa, ou mesmo que não querem quebrar o vínculo com o mercado de trabalho, conseguem manter-se na prática pedagógica ao conduzir seus cursos de uma forma autônoma, livre e experimental.

Foi após um ano de trabalho como professora de língua portuguesa para estrangeiros ${ }^{3}$ que apresentei à coordenadora pedagógica (e também proprietária, a francesa Audrey Conjat) o curso de Literatura Brasileira para Estrangeiros. Tive a ideia por perceber-me frequentemente trazendo textos literários

3 Em todo o artigo, optei por usar a sigla PBLE (Português Brasileiro Língua Estrangeira) já que as especificidades da língua portuguesa falada no Brasil foram constantemente um foco de atenção nos debates sobre a escrita literária brasileira. 
para as aulas de língua e tendo boa receptividade da parte dos alunos, o que me punha em contato com a necessidade de reflexão sobre o ensino do texto literário no contexto da sala de aula de língua estrangeira.

Muito do que conduzia vinha das minhas formaçóes acadêmicas, mas muito vinha de mim como leitora ativa e da prática como tradutora de poesia. Eu sabia que caminhava em um terreno já um pouco conhecido, mas também muito novo, e achei que precisava explorar essa prática que parecia unir diversas áreas de interesse e levar o ensino de língua para outra dimensão.

Após entregar o planejamento, recebi como resposta a ressalva de que, claro, sem alunos o curso não teria como existir, junto com o comentário de que talvez o curso tivesse um caráter "muito acadêmico e sério"; o nome foi então mudado para "Literatura Brasileira em 10 passos", com a justificativa de que assim ficaria mais moderno e mais atrativo para os alunos. $\mathrm{O}$ processo de divulgação foi feito pelo instituto basicamente de forma on-line. Tivemos quatro alunas adultas inscritas: uma austríaca, uma sueca e duas francesas, e o curso ocorreu de maio a julho de 2015 com a carga horária de vinte horas (dez aulas com duas horas de duração cada, às sextas-feiras $)^{4}$.

O curso teve por objetivo oferecer um panorama em que importantes autores e movimentos fossem discutidos e estimular o gosto pela leitura, formando assim leitores independentes que soubessem navegar pela literatura brasileira. Técnicas de debate comparativo acerca das obras foram muito satisfatórias, e as alunas entravam em contato com duas ou mais obras de cada movimento ou autor por aula temática.

A dificuldade de trabalharmos completamente uma ou mais de uma obra literária por semana é evidente; e, de fato, esse não foi o objetivo. $\mathrm{O}$ foco foi sempre a apresentação, a introdução, a criação de uma identidade possível entre as alunas estrangeiras e os temas, as técnicas e as características que permeiam a literatura brasileira. Previamente a cada aula, as alunas deveriam ler trechos selecionados das obras ou, em algumas aulas, ler livremente quantas e quais páginas quisessem das obras indicadas. Com a leitura, era encaminhada uma questão para guiar um pouco o olhar delas, uma atividade pré-leitura, como, por exemplo, identificar as descriçôes e analisar o valor dado às personagens indígenas em Iracema, de José de Alencar, e em Órfäos do Eldorado, de

4 O planejamento que entreguei para a escola e que foi a estrutura do curso está em anexo ao final deste artigo. 
Milton Hatoum, em uma aula em que a tradição indigenista da literatura brasileira era o foco. Em outra, deveriam identificar técnicas de estilo e temas dos poetas da tradição paulista em relação a expoentes das outras regiōes do país, como Manoel de Barros (MS), Adélia Prado (MG) e Mário Quintana (RS). Em outra, ainda, deveriam atentar para a construção do eulírico em Cora Coralina e trazer passagens em que a poesia estivesse mesclada com a prosa, em uma aula em que abordamos a influência do causo como gênero oral do interior do Brasil na escrita da autora. Tudo o que as alunas deveriam fazer era ler livremente e trazer suas consideraçóes sobre o que fora pedido para o debate em sala de aula que, naturalmente, se encaminhava daí para diversas outras questôes. Também alguns vídeos curtos, disponíveis on-line, de autores falando sobre suas escritas foram assistidos em aula, e trechos de artigos da crítica literária especializada foram lidos e debatidos, servindo como fonte de reflexão. Assim, o formato de debates pode ser seguido sem maiores cobranças ao longo das dez semanas 5 .

O perfil das alunas foi bastante condizente com o esperado no momento do planejamento, mas também o superou em termos de envolvimento com a literatura. Tratava-se de pessoas em condição de expatriação no Brasil ou casamento com brasileiros, todas profissionais com experiências internacionais (uma atuava como professora universitária de Relaçôes Internacionais, as demais com direito e economia) e com domínio de outras línguas além da materna. Todas já tinham o hábito da leitura. Inscreveram-se no curso porque tinham interesse particular pela literatura brasileira e porque buscavam um espaço em que pudessem falar o português livremente, pondo em prática o que já tinham estudado formalmente. Ou seja, já vieram para o curso com as condiçóes mais satisfatórias que poderíamos esperar: tinham o interesse na literatura, o hábito de ler e um domínio considerável da língua portuguesa.

Nesse sentido, a experiência que relatamos aqui foi muito privilegiada. Tivemos dificuldades outras das comumente encontradas nos cursos de literatura das escolas brasileiras, a saber, o grande número de alunos por sala, a necessidade da criação e do despertar do interesse pela leitura, a manutenção da concentração e disciplina etc. As que encontramos se situavam mais entre

5 Até o final do curso, uma aluna chegou a ler uma obra completa em uma semana, o que, segundo ela, foi muito gratificante. Tratou-se da contemporânea Todos nós adorávamos caubóis, de Carol Bensimon. 
os diferentes domínios de cada aluna acerca da língua e de aspectos da cultura brasileira; a necessidade da criação de estratégias que pudessem levar ao desenvolvimento dos mesmos tendo como foco as obras; e, sobretudo, a de construir, ao longo do curso, a confiança e a liberdade de adentrarem a experiência da alteridade em obras brasileiras de forma independente e que pudesse permanecer para o futuro.

Embora nós não possamos garantir que isso tenha sido conquistado, por causa do tempo que leva para poder ser constatado, acreditamos que este estudo de caso pode oferecer algumas reflexôes sobre o trabalho com literatura brasileira no contexto de sala de aula para estrangeiros, sobretudo no que diz respeito ao que Bloom defende como a importância do nosso crescimento individual como leitores: "O estudioso é uma vela acesa pelo afeto e pelo gosto de toda a humanidade” (2001, p. 20). É essa vela acesa que me levou à criação do curso e guiou a condução de cada aula; essa é a chama que deveria manter-se acesa nas alunas-leitoras estrangeiras a cada leitura e deverá, espero, seguir com cada uma ao deparar-se novamente com a leitura de uma obra brasileira.

\section{A reflexão acadêmica sobre o ensino de literatura no ensino PBLE}

Apesar da prática do ensino de literatura brasileira para estrangeiros ser nova em território nacional, a academia já apresenta uma discussão sobre o uso do texto literário na sala de aula de PBLE. A mesma se dá, mais amplamente, em publicaçóes de professores dos cursos de PBLE existentes nas universidades brasileiras, nos quais serão os próprios professores do departamento de Letras que conduzirão as aulas, mas também poderão ser os alunos de graduação e pós-graduação que, sob suas supervisões e orientações, terão a chance de assumir-se como professores e de atuar como pesquisadores de grupos de pesquisa. Vamos, então, pôr em discussão as conclusôes de três publicações recentes de diferentes níveis acadêmicos: o trabalho de conclusão de curso de Melissa Kuhn Fornari (UFRGS), a dissertação de mestrado de Neide Tomiko Takahashi (USP) e a tese de pós-doutorado da Profa. Dra. Regina Sellan (PUC-SP) defendida na Universidade Federal Fluminense, atentando, sobretudo, às razóes que apresentam para o trabalho com literatura na sala de aula de língua estrangeira. 
Sellan (2014) e Takahashi (2009) analisam, nos livros didáticos usados em cursos de PBLE, a presença das atividades com o texto literário e como elas se dão. Ambas as pesquisadoras concluem que o livro didático apresenta insuficiências neste sentido. Segundo Takahashi, o emprego do texto literário nos materiais de PLE é

mínimo, até mesmo nulo, e sem regularidade na apresentação e nas propostas. Em geral, eles se reduzem a (poucos) textos curtos - na maioria crônicas e contos -, que têm a intenção de apresentar um perfil da cultura brasileira ao lado de letras de músicas, excertos de textos jornalísticos, publicitários ou, mais raramente, de história. Isso inclui afirmar ainda que, no Brasil, os estudos sobre literatura, leitura e ensino literário em português também não foram suficientemente analisados e aprofundados em sua perspectiva didática de língua estrangeira (LE) (TAKAHASHI, 2008, p. 11-12).

Caberia, então, ao professor repensar os materiais para a criação de suas aulas. As pesquisadoras indicam que o texto de literatura pode contemplar a união necessária entre gramática e texto em atividades mais complexas que visem ao ensino de aspectos da cultura brasileira, sendo indicado por ser um material autêntico e representativo da cultura do povo que o aluno estrangeiro está em vias de descobrir: "Consideramos que o texto literário - e o discurso nele representado - é uma forma de construção da memória social, cultural e histórica de um povo, pois constitui representaçóes desse povo a partir da visão de dado momento histórico-cultural, sob a ótica, por exemplo, de escritores e poetas" (SELLAN, 2014, p. 12).

Takahashi (2008, p. 62-65) verifica que os alunos estrangeiros valorizam estudar português a partir de textos literários, pois afirmam encontrar neles usos reais de vocabulário e gramática, bem como uma boa amostragem das questôes culturais próprias ao Brasil.

Vemos a defesa da "literatura como objeto de ensino integrante do processo de aprendizagem da língua e na construção e percepçáo de contextos culturais propiciados pelo contato com a literatura” (SELLAN, 2014, p. 16). Assim, a literatura é vista "como forma de representação social e cultural do 
grupo a que "pertence" a nova língua aprendida" (SELLAN, 2014, p. 15), e os textos literários brasileiros recebem o respaldo de material autêntico a ser utilizado em sala de aula para estrangeiros, por ser uma via de acesso à cultura brasileira e também por permitir o trabalho de abertura intercultural na aceitação das diferenças:

Se considerarmos o paradigma atual, cuja abordagem propóe a interculturalidade, trabalhar a literatura surge como um modo de valorizar as diferenças e, consequentemente, desenvolver a compreensão de que as diferenças existem [...]. Por essa razão, as práticas pedagógicas devem favorecer a uma comunicação mais global, sem fronteiras restritivas, de modo a realçar o diálogo entre as culturas. Talvez aqui esteja clara a definição de Antonio Candido sobre a força humanizadora da literatura (SELLAN, op. cit., p. 80).

Além da compreensão cultural aprofundada, um dos aspectos fundamentais levantados por Sellan sobre o estudo do texto literário (em contexto PBLE ou em qualquer outro), pode levar ao entendimento da própria literatura: "a literatura pode propiciar procedimentos de aprendizado muito mais amplo, não apenas da língua, mas inclusive da própria literatura, da cultura e da identidade do povo de que é referência" (SELLAN, op. cit., p.12).

Nesses dois casos, as pesquisadoras debatem sobre a inserção da literatura como conteúdo da aula de língua portuguesa e cultura brasileira para estrangeiros. Atividades comuns relacionadas com o uso do texto literário na aula de língua estrangeira seriam:

compreensão (leitura e interpretação); o reconhecimento de palavras (explicação do léxico), de referentes e conectores (articulaçóes dos textos); as estruturas da narrativa (tema, personagem, tempo, lugar, entre outros); as estruturas gramaticais (morfossintaxe) e, especialmente no caso dos poemas, os recursos fonéticos (pronúncia, aliteração, assonância e rima) (TAKAHASHI, 2008, p. 67). 
Entretanto, os textos literários vão além, servindo "para o desenvolvimento da comunicação em língua estrangeira tanto por serem autênticos, em oposição à 'fabricados para o curso', quanto por integrar fatores culturais e serem utilizados como instrumentos no processo de apropriação do discurso do outro" (TAKAHASHI, 2008, p. 12).

O curso da UFRGS apresenta módulos que tratam a literatura enquanto objeto de estudo a ser compreendido em si mesmo, tal qual a nossa proposta de curso. Fornari (2006), ao apresentar sua reflexão sobre o curso de "Contos e crônicas" que conduziu na UFRGS em 2005, segue o pressuposto de que língua e cultura são indissociáveis, mas faz a ressalva de o foco, em algumas representaçóes culturais que podemos considerar como importantes, poder excluir outras, o que pode nos conduzir a criar exotizaçóes sobre a nossa própria cultura:

Podemos considerar a Bossa-Nova como uma representação importante da cultura brasileira, porém, não em detrimento de outras manifestaçóes culturais da música que também são representativas para outros grupos nessa cultura. A manutenção da ideia de que só a Bossa-Nova seria a representação da cultura brasileira é um caminho reducionista e discriminatório, pois privilegia um determinado estilo e exclui os demais. Neste caso, onde ficaria o fandango do Sul ou o frevo do Norte? E as bandas de rock das grandes cidades? E o cordel nordestino? E o funk carioca? (FORNARI, 2006, p. 10-11).

Questionando o uso do texto literário somente como acesso aos aspectos culturais do Brasil, entende-se a "literatura como arte, como uma representaçâo feita através de palavras que expóe ou mostra essas verdades, aqui entendidas como questôes que fazem parte de uma determinada realidade" (FORNARI, 2006, p.14). Nesse sentido, traz para a discussão o fato de que devemos compreender "um texto literário ou artístico tendo como principal critério a questão da forma, não é especialmente o que é expresso no texto que lhe atribui o caráter de literário, mas como, que é definido pelo mesmo autor como forma estética" (grifos do original). 
Assim, as atividades que propóe estão mais focadas no desenvolvimento de habilidades que no aprimoramento linguístico:

Consideramos os textos literários como um material muito rico a ser explorado na aula de língua. De forma ampla, além do desenvolvimento da prática da leitura e do trabalho com essa habilidade, é possível abordar as demais habilidades: a habilidade oral, a partir de discussões sobre os textos lidos, nas quais o aluno pode expor sua interpretaçáo, argumentar, opinar etc.; a habilidade da escrita, através de tarefas de produção textual baseados na leitura dos textos e a compreensão oral, através da utilização, por exemplo, de materiais de áudio (como poemas declamados, musicados, entre outros). A literatura pode contribuir para uma aproximação mais profunda entre o aluno e o universo da língua alvo, proporcionando o contato com questóes culturais, diferentes visôes sobre uma mesma realidade, formas de representação dessa realidade, diferentes registros e variados usos de recursos linguísticos. Além disso, citamos também o desenvolvimento da capacidade de interpretação, de uma prática de leitura mais aprofundada, do trabalho com a imaginação e com a criatividade resultando em uma abordagem que contribui para a formação integral do estudante de língua estrangeira (FORNARI, 2006, p. 17).

Para finalizar, segundo a pesquisadora, o objetivo de "proporcionar o prazer estético e catártico através da presença do aspecto artístico e lúdico do texto literário como parte integrante da aula de língua" (FORNARI, 2006, p. 18) precisa também ser levado em conta.

\section{Da prática à reflexão}

A bibliografia acadêmica que discute a literatura no contexto PLE mostra-se aberta para a inclusão da literatura brasileira, sobretudo contos e crônicas modernos e contemporâneos, nas aulas de português (brasileiro) como língua estrangeira. As autoras citadas realizam uma importante defesa do porquê da inclusão do texto literário e revelam procedimentos de ensino de compreensão 
textual e de desenvolvimento de habilidades que muito podem ajudar os atuais e futuros profissionais da área. Os textos literários aparecem principalmente como uma ferramenta privilegiada para o ensino de aspectos da cultura brasileira, indo além da expansão vocabular e gramatical que, por meio deles, pode ganhar maior contextualização e proporcionar maior contato com usos reais da língua no Brasil. A questấo do gosto da leitura, da experiência de ver o mundo pelo olhar do outro e da necessidade de, em curso de literatura, estudarmos a própria literatura são aspectos mencionados por Sellan e desenvolvidos por Fornari. Acreditamos que merecem ainda maiores pesquisas no contexto do ensino PBLE. Nosso intuito, na criação do curso de Literatura Brasileira para Estrangeiros, foi exatamente de estudar a literatura pela literatura, posicionar a questão do prazer da leitura como central e desenvolver, como principal objetivo, o alcance da experiência da alteridade que somente a literatura pode proporcionar. Assim, buscamos trazer algumas questóes próprias da natureza e função da literatura para o ensino da literatura no contexto PBLE.

André Dias (2015), analisando a crise da leitura na escola, indica que a atual proposta dos PCNs, de junção das áreas de Literatura e Línguas, embora tenha contribuído para diminuir o isolamento entre os saberes, levou a uma crise do ensino da literatura a partir da premissa de que "o estudo da gramática passa a ser uma estratégia para compreensão/interpretação/produção de textos e a literatura integra-se à área de Leitura” (PCN, 1996, p.17 in Dias 2015). Assim, a escola brasileira passou a apresentar uma "paulatina perda de espaço do ensino formal de Literatura e o estrangulamento de um canal importante de formação de leitores", chegando mesmo a uma atual "reduçáo drástica de Literatura como disciplina autônoma” (DIAS, 2015, p.11).

Ou seja, gostaríamos de ressaltar que, neste interessante movimento de abertura da área de PLE para o uso do texto literário em sala de aula, é de suma importância adentrarmos cada vez mais algumas especificidades do campo literário. Por mais que as nossas situações sejam bastante diferenciadas em relação à realidade da escola pública, a atenção ainda é necessária a fim de que o texto literário se mantenha enquanto tal em sala de aula e toda a sua literariedade $^{6}$ seja objeto de discussão e compreensão por parte dos alunos estrangeiros (ou nativos). Dias alerta para o fato de que

6 Para maior aprofundamento no conceito, ver ACÍZELO DE SOUZA, Roberto. Teoria da Literatura. São Paulo: Ática, 2007. p. 48-51. 
$\mathrm{Na}$ maioria das vezes o que se tem tanto nos currículos, quanto nos livros didáticos é um arremedo, um tanto confuso, de História da Literatura, de Crítica Literária, de Teoria da Literatura e de Literatura, sem, no entanto, representar bem nenhum desses elementos. Tal fato torna o ensino de Literatura e, por extensão, o trabalho de leitura e formação do leitor muito mais árido do que se poderia supor (DIAS, 2015, p. 12).

Foram algumas dessas especificidades que tentamos manter como centrais na condução das aulas do curso de Literatura Brasileira para Estrangeiros, a saber, a função estética, a verossimilhança interna e externa, a materialidade criativa do texto e os efeitos de sentido presentes em cada obra. Isso porque entendemos que o domínio de questóes da literariedade poderiam ajudar as alunas a vivenciar as experiências estéticas próprias de cada obra e, portanto, a experimentar a alteridade na sua mais completa dimensão. Nesse sentido, a leitura prévia e o livre debate assumiram-se como as principais atividades do curso, uma vez que ajudá-las a tornarem-se verdadeiras velas acesas à literatura brasileira e leitoras independentes eram os nossos principais objetivos. Assim, a condução do debate precisou aventurar-se por diversas possibilidades interpretativas dos textos (e aí o conhecimento de mundo dos diferentes alunos advindos de diferentes culturas foi muito rico e levou as discussóes por direçóes que não poderiam ter sido previstas) e, também, estar alinhado com questóes próprias da história e teoria da literatura, lançando mão por vezes de textos críticos que foram usados como suporte de discussóes ou mesmo via de acesso a questóes intrínsecas às obras. A leitura profissional dos críticos brasileiros foi muitas vezes fundamental para situar as leitoras estrangeiras nas obras e/ou em possíveis debates da área.

Portanto, acreditamos que, mesmo nos casos em que o curso em questáo seja o de ensino de língua, e não propriamente da literatura brasileira, e a literatura apareça mais como um meio (de acesso à cultura) do que para um fim (entendimento da própria literatura brasileira), o percurso por questóes da própria literatura se faz necessário. $\mathrm{O}$ atual interesse da área de PBLE pela união com a literatura em muito vai se beneficiar ao mesclar, a cada discussão de uma obra e/ou trecho de obra, conceitos e pontos de vista existentes na história, teoria e crítica literária. Somado a isso, questóes próprias do ensino 
da literatura precisarão ser adentradas, e talvez passar por adaptaçóes, modificaçóes ou replanejamentos no contexto do ensino para estrangeiros.

Loyola (2015) mostra a necessidade da superação da distância existente atualmente, dentro dos estudos literários, entre a área do ensino de literatura e da literatura em si. O paradoxo ético versus estético é visto, de acordo com a autora, como a explicação do porquê os estudos acadêmicos tenderem a contempla-las separadamente, uma vez que o vetor ético e muitas vezes moralizante da área da educação pode ser opor ao não comprometimento com a ética, ou com o questionamento de valores, da literatura. Entretanto, o professor, como mediador de leitura literária, que tem clareza sobre a experiência da alteridade que o literário pode de fato proporcionar, precisa unir ambas as áreas na prática de sala de aula.

Por isso, é importante ressaltar que os conceitos e pontos de vista especializados da área da literatura não podem fechar as discussóes como verdades inquestionáveis. A literatura possibilita uma experiência da alteridade de uma forma muito particular. Convive-se com e adentra-se um outro que é criado pela palavra, numa instância que não é a realidade, mas também não é oposta a ela. Loyola afirma que essa é a

principal importância no processo de formação, isso é muito valioso. Construir um modo de ser mais firme, já que as relaçóes que construímos com as personagens são muito distintas de leitor para leitor, logo, cada leitor vai experimentar a alteridade de forma distinta, reforçando o que em cada um é singular. $\mathrm{O}$ mediador precisa saber acolher isso (Loyola, 2015, parte 1).

Ou seja, a acolhida da subjetividade é um dos principais feitos que podemos realizar enquanto professores-mediadores de leitura, tanto em uma aula de literatura, quanto em uma aula de língua em que uma atividade tenha o texto literário em foco. Mas como acolher diversas subjetividades muitas vezes nascidas em culturas às quais não temos acesso? Esse foi o desafio com que me deparei a cada aula, e a estratégia de incentivar as alunas a expressarem livremente suas experiências com cada obra foi a mais óbvia, mas também a mais proveitosa durante todo o curso. Primeiro, porque não podemos perder de vista que, além de conhecer a literatura brasileira, as alunas queriam um 
espaço em que pudessem falar livremente e ouvir o português brasileiro, e o fato de externar uma experiência subjetiva possibilita um uso da língua que talvez elas ainda não tivessem posto em prática (e talvez não tenham tido outra situação de o fazer durante a vivência no Brasil). Segundo, porque assim eu teria alguma noção do conhecimento prévio delas sobre os temas tratados, ou sobre as relaçóes que faziam com o conhecimento de mundo que já tinham, a fim de poder mediar um pouco as discussōes no sentido de navegar cada vez mais profundamente pela literariedade de cada obra e, assim, ajudá-las no caminho à experiência da alteridade.

Isso foi necessário porque ficar somente na leitura subjetiva pode também ser muito equivocado. $\mathrm{O}$ embate entre a relação subjetiva do leitor e o estudo do texto deve ser mediado para promover o encontro do aluno com a obra. Precisamos saber fazer a junção necessária entre ensino de literatura e literatura, tendo em mente que "no estudo da literatura, esta categoria [do leitor implícito] será sempre implícita, virtual e já dada; quando eu contemplo a relação da literatura e do ensino, eu preciso me deslocar dentro dessa categoria, e considera-la real e empírica” (Loyola, 2015, parte 1). Este é o grande desafio, tanto em língua materna como estrangeira; e, em uma aula com alunos estrangeiros, algumas questôes culturais e linguísticas podem facilmente ocupar todo o espaço se não tivermos em mente a condução pela literariedade da obra.

Ainda, é preciso garantir que a união prazerosa se estabeleça entre os alunos e a leitura das obras que nós, ao criarmos o curso, conduzidos tanto pelo cânone, quanto pelo perfil que sabemos ou antevemos dos alunos, acabamos por unir como conteúdo obrigatório. "Essa experiência [do prazer da literatura], uma vez adquirida, acredito que não é perdida nunca mais. E o exercício dela é fatalmente seletivo. A partir daí, o leitor adquire instrumentos próprios para suas seleçóes" (Loyola, 2015, parte 3).

Como professores-mediadores, temos que ter claro também qual é a nossa experiência com a leitura de cada obra e não devemos subestimar a capacidade de os alunos estrangeiros entenderem os clássicos, a poesia, os experimentalismos contemporâneos, mesmo que o domínio linguístico deles seja diferente do domínio que os alunos nativos possam ter. Por isso, usar a literatura para fins de ensino de língua e cultura tem sua validade e, de fato, enriquece as aulas de PLE, mas vivê-la como real experiência literária, com livres leituras individuais prévias e discussão em sala sobre a obra, seus efeitos e as 
formas pelos quais se dão não é fazer pouco. Muito pelo contrário, o prazer do contato com o literário e da troca das experiências com o texto pode ser uma atividade muito enriquecedora no nível da aquisição e atualização da língua e vai além da competência que pode ser alcançada com o aprendizado formal. Nela, o aluno vai, individualmente e de forma ativa, criar suas hipóteses, testá-las, fazer conexões próprias para manter o diálogo com o texto, preencher suas lacunas e dar-lhe sentido. Criar o momento de pôr esse processo em discussão é fundamental, e exige que o professor esteja devidamente capacitado para silenciar-se, ouvir e, muitas vezes aprender ou passar a questionar algo que tinha por certo, confiando no poder que os conhecimentos de mundo de seus alunos estrangeiros podem ter para a compreensão da literatura brasileira e para o prazer de sua leitura.

Claro que isso demanda alunos de níveis mais avançados, mas pode também ser uma forma de ajudar a desenvolver a independência de alunos intermediários. O perfil das alunas desse curso situava-se entre ambos, e muitas vezes aspectos linguísticos e culturais foram o foco da discussão ou precisaram ser esclarecidos a fim de podermos adentrar o texto de uma forma mais profunda. Por exemplo, a figura do retirante e do caipira foram tópicos de discussão da segunda aula, o que de fato colocou uma obra como Vida secas como ilustrativa de uma realidade cultural. Porém, essas figuras foram melhor compreendidas visualmente em obras de arte modernas e contemporâneas na aula em que fomos à Pinacoteca do Estado de São Paulo e, de volta à sala de aula, puderam ser debatidas em relação à obra: a estrutura de pensamento fragmentado e gutural de Fabiano e sinhá Vitória, a forma de criação das miragens das personagens, quando as alunas puderam perceber como o autor se aventura pelo fazer poético, e a relação entre os animais e os humanos foram alguns focos necessários de análise para termos a possibilidade de adentar a visão interior do retirante, que é o grande feito da escrita de Graciliano Ramos. Nesse sentido é que, acredito, pudemos viver a experiência estética nesta obra, mesmo com alunos de diferentes origens e com diferentes domínios da língua.

Por isso, reforçamos o interesse em explorar o contato com a obra literária para além da ilustração de aspectos culturais brasileiros. Afinal, estes retirantes só existem em e por Vidas secas. Suas especificidades, a forma pela qual existem e o modo pelo qual se relacionam com, afirmando ou questionando, um possível conceito maior e extraliterário do retirante e da condição dos imi- 
grantes nordestinos durante o processo de modernização do Sudeste precisam ser debatidas, se quisermos adentrar, de fato, a escrita graciliana e usar o texto literário enquanto tal na sala de aula de língua estrangeira. Se o que caracteriza uma obra literária é a experiência da alteridade que ela proporciona, e o prazer de leitura vem dessa experiência, que é estética, isso precisa ser contemplado ao trabalharmos literatura em sala de aula, seja com alunos nativos ou estrangeiros. Mesmo que o aluno-leitor possa não chegar ao compartilhamento com o olhar do outro, algumas vias de entrada precisam ser abordadas para que, no futuro, e se tiver interesse, o aluno tenha a chance de ser um leitor ativo e independente e traçar essa experiência com esta ou outra obra literária.

Ainda nesta aula, a situação do retirante, que pode comumente ser visto como típica da cultura brasileira e do processo histórico de migração interna que tivemos, foi comparado por uma aluna aos movimentos migratórios internos entre os países da Europa e da realidade rural desses migrantes. Outra ainda conectou esse foco temático de Graciliano ao de romances norte-americanos escritos em meio à crise de 1929 , ora, data próxima da publicação de Vidas secas no Brasil (1938). Isso nos revela que as livres conexóes a partir dos conhecimentos de mundo dos alunos são muito eficazes para a entrada no texto, e é isso que indicamos que precisa ser estimulado. Caberá a nós, após este processo, guiar para as especificidades do tema, da obra e da escrita do autor, já que deixar livre a reflexão que esses personagens são os mesmos das migrações europeias, ou que Vidas secas é mais um dos romances norte-americanos surgidos no contexto da crise, seria, além de limitador, falso. A obra teve sua recepção possibilitada em relação às mesmas, e essas relações nos parecem, à primeira vista, bastante válidas. Mesmo se não nos parecessem, precisariam ser estimuladas, pois é esse tipo de entrada que nos permitirá desenvolver a literariedade da obra em questão na sala de aula com alunos estrangeiros.

Em outras aulas, fui surpreendida pela distância, e ao mesmo tempo proximidade, dos comentários em relação às análises especializadas. Por exemplo, não ficaram muito maravilhadas com Machado de Assis devido ao fato de terem considerado sua escrita similar a de outros escritores europeus com as quais já tinham bastante familiaridade, sobretudo ingleses. Por outro lado, uma aluna francesa (filha de inglês e casada com inglês) gargalhou em passagens de $A$ cartomante que muitas vezes podem passar despercebidas; o que mostra a grande conexão dela com o texto ou, ao menos, com os efeitos de 
humor presentes na escrita machadiana. Esta é uma situação que prova que as diferenças entre os níveis linguísticos de português de um aluno-leitor estrangeiro em relação a nossa (enquanto nativos ou professores de português) não são sempre o maior problema para experimentar realmente um texto literário. Outras questôes, que dizem respeito ao acesso ao outro e à experiência da alteridade, também estão em jogo e precisam passar a fazer parte das nossas reflexôes se quisermos expandir o conhecimento sobre o ensino de literatura brasileira para estrangeiros.

Ao longo das aulas, aprendi sobre autores austríacos, alemães, russos e indianos quando as alunas eram questionadas sobre semelhanças com temas ou técnicas da obra brasileira que estávamos lendo com algo que já conheciam. Nestes momentos, percebi que precisamos entender que a relação com o cânone sofre, no contexto em que todos os alunos são estrangeiros, algumas influências que vêm de fora das consolidaçóes internas formadas pelos estudiosos da área.

Por exemplo, pela valorização do conhecimento prévio dos alunos, seus gostos e interesses, um dos conteúdos que precisou aparecer foi a escrita de Paulo Coelho, autor negado pela academia por não ser visto como representante de nenhum movimento fundacional da literatura brasileira. Porém, negar a informação já sabida por todo professor com alguma experiência com alunos estrangeiros - a de que os alunos conhecem Paulo Coelho, assim como conhecem Pelé e o samba - seria errôneo.

De fato, três das quatro alunas já tinham lido algum livro dele em suas línguas maternas, e a única que não o fizera já tinha também algum conhecimento sobre seus temas (que não a convinham pessoalmente, por isso disse não ter lido). Ou seja, Paulo Coelho era o único autor que todas conheciam antes de começar o curso. Vindos de ambientes fora do Brasil onde o sucesso do autor como best-seller pode levar a crer que se trata efetivamente do maior escritor brasileiro, os alunos trazem uma ânsia de lê-lo que entendi que não poderia ser ignorada em um curso de literatura brasileira para estrangeiros. Assim, tentei contextualizá-lo no planejamento em um tópico intitulado "Quando a literatura brasileira se torna best-seller internacional: o caso Paulo Coelho”, quando, após termos lidos representantes canônicos, pudemos analisar as diferenças de temas e de estilo de escrita, em uma abordagem comparativa, e também conhecer a discussão da exclusão acadêmica do autor e a apreciação pelo público leitor nacional e internacional. 
Tentei não colocar o best-seller numa relação de competição com as demais obras, mas conduzir de maneira a "mostrar ao aluno que ele tem direito ao acesso a esta experiência e que ela, pela sua própria singularidade, pode também contribuir muito para que ele aproveite, da forma mais ampla possível, o seu estar no mundo" (Loyola, 2015, parte 3).

Nessa aula, presenciei a construção de significados conjuntos que revelaram a existência de um conhecimento de mundo internacional do qual o Brasil também passou a fazer parte nos últimos anos. Isso ficou bastante claro quando analisamos, na mesma aula, a letra da música Eu nasci há 10 mil anos atrás, de um álbum que o autor escreveu em parceria com Raul Seixas. Nela, símbolos e questóes internacionais são apresentados em uma sequência de colagens aparentemente aleatórias, como parte de um conhecimento de mundo de alguém que nasceu com a origem do mundo, ou seja, que representam uma ideia junguiana de inconsciente coletivo e que, artisticamente, funcionam como uma tentativa universalizante da música de Raul Seixas/Paulo Coelho.

Foi interessante perceber como, ao longo da discussão, as alunas indicaram a relação entre a ocidentalização do mundo e a espiritualidade como assunto temático dos livros de Coelho contemplados na aula. A ocidentalização do mundo, que não era nenhuma novidade para estas alunas (as quais, como já indiquei, possuíam alto nível de leitura literária e sociológica e grande experiência de viagens para diversos países e continentes), foi, então, explorada com o objetivo de reposicionamento do olhar das alunas-leitoras perante o Brasil. Discutimos a ocidentalização do mundo e a carência espiritual advinda dela tal qual sentida pela população de diversos países nos anos anteriores à virada do século, e as formas pelas quais o autor insere essa ansiedade dita universal em estrutura narrativa, distanciando-se dos temas consagrados da literatura brasileira e tentando dialogar com as literaturas internacionais. Algumas estratégias literárias do autor pudemos perceber juntas, entre elas, o início das estórias aos moldes dos romances franceses do século XVIII, em que um personagem peregrino conta uma história que ouviu de alguém que a teria vivido, o que cria o efeito de dissolução dos limites entre ficção e realidade e permite a construção de algumas imagens entre o real e o imaginário/espiritual.

Por fim, na tentativa de contemplar o processo inverso, da entrada de escritores estrangeiros na circulação nacional, tive a oportunidade de discutir meu trabalho como tradutora de poesia e ouvir questóes, críticas e sugestóes. 
Também pudemos discutir a realidade das publicaçóes nas revistas literárias contemporâneas no Brasil e debater algumas questóes próprias da tradução como forma de fazer literário.

Ou seja, o grande desafio do curso, acredito, foi também a sua maior conquista: tratar a todos nós como leitores reais, permitindo-nos o espaço para a expressão das subjetividades e, ao mesmo tempo, reservando espaços a cada aula para adentrar algumas visóes já consolidadas pela crítica literária. A fim de podermos debater com ela, trazendo a nossa experiência de leitura e os nossos questionamentos, apropriamo-nos cada vez da história e teoria literárias, para que, assim, as alunas pudessem ativar as entradas à experiência da alteridade e posicionar-se, pela primeira vez, como leitoras independentes de literatura brasileira, indiferentemente de suas origens e do nível que cada uma tinha do domínio da língua.

E talvez por terem se formado leitoras de literatura brasileira é que se sentiram instigadas pela língua portuguesa como um todo. Partiu da turma, na última aula, a ideia de um novo curso, para o segundo semestre, sobre as literaturas de Portugal e da África lusófona e sobre a música brasileira. Espero que este seja o tema de um outro artigo no futuro.

\section{Referências}

ACÍZELO DE SOUZA, Roberto. Teoria da Literatura. São Paulo: Ática, 2007. BLOOM, Harold. Como e por que ler. Trad. José Roberto O’Shea. Rio de Janeiro: Objetiva, 2001.

DIAS, André. "A crise da leitura e a formação do leitor: impasses e perspectivas", in Dias, A. et all. Leitura e formação do leitor: cinco estudos e um relato de experiência. Rio de Janeiro: Editora 7Letras [no prelo].

FORNARI, Melissa Kuhn. O texto literário na aula de lingua estrangeira: um olhar, uma possibilidade, uma experiência. Trabalho de conclusão de Licenciatura em Letras sob a orientação da Profa. Dra. Margarete Schlatter. Porto Alegre: UFRGS, 2006.

LOYOLA, Juliana. "Literatura, ensino e a formação do leitor: a experiência da alteridade" Entrevista audiovisual. Partes 1 - Literatura e ensino e a experiência da alteridade e 3 - Literatura, ensino e o leitor real. Fronteira n.14 2015. Disponível em http://revistas.pucsp.br/index.php/fronteiraz/issue/view/1358 
MONTEIRO, Paulo Meira (Org.). A primeira aula: trânsitos da literatura brasileira no estrangeiro [recurso eletrônico]. São Paulo: Itaú Cultural, 2014.

SELLAN, Aparecida Regina Borges. Textos de literatura: inserção e abordagem em livros didáticos de PBLE. Pesquisa de Pós-Doutorado sob supervisão da Profa. Dra. Norimar Pasini Mesquita Judice. Niterói: UFF, 2014.

TAKAHASHI, Neide Tomiko. Textos literários no ensino de português-língua estrangeira (PLE) no Brasil. Dissertação de Mestrado sob orientação do Prof. Dr. Reginaldo Pinto de Carvalho. São Paulo: USP, 2008.

\section{Anexo I}

Planejamento do Curso de Literatura Brasileira para Estrangeiros Professora: Ana Amália Alves

Pré-requisitos: Ter completado o módulo A2.2 ou algum módulo posterior. Caso o(a) aluno(a) ainda não tenha estudado na aprenda ${ }^{2}$, mas saiba que seu nível de português está entre intermediário-avançado também poderá participar.

Objetivos: Conhecer autores e obras famosas da literatura brasileira, desde o século XIX até os dias atuais.

Estrutura do curso: 10 aulas de $2 \mathrm{~h}$ de duração. A cada aula, leremos, de forma comparada, trechos ou capítulos de importantes livros de romance, contos, crônicas e poesia, a fim de que, até o final do curso, o(a) aluno(a) consiga ter uma noção da amplitude e das várias expressôes da literatura brasileira ao longo dos anos. Assim, não focaremos em ler apenas um livro, mas em gerar repertório suficiente para que sejam leitores independentes de literatura e poesia brasileira no futuro. O curso também contará com uma aula na Pinacoteca do Estado de São Paulo, a fim de visualizarmos algumas relaçóes entre literatura e artes plásticas no Brasil, e com discussões sobre algumas traduçôes de poemas do inglês para o português feitas pela professora e publicadas em diferentes revistas literárias e jornais atuais. 
A professora: Ana Amália Alves é professora na aprenda2 há um ano. Ela tem 8 anos de experiência em ensino de língua estrangeira (português e inglês) e também atua com formação continuada de professores das escolas pública e privada e tradução literária. Foi professora visitante no programa de mestrado em Translating Popular Culture, da City University London, e possui mestrado em Spanish, Portuguese and Latin American Studies pela King's College London, onde analisou a recepção da obra da escritora brasileira Clarice Lispector no Reino Unido. Algumas de suas traduçóes foram publicadas em revistas como Polichinello, Zunái e portal Opera Mundi da Uol.

\section{Conteúdo:}

Aula 1: A formação da sociedade carioca. Autores: Aluísio Azevedo, José de Alencar e Machado de Assis. Livros: O cortiço, Lucíola e Memórias Póstumas de Brás Cubas.

Aula 2: Modernismo e regionalismo. Autor: Graciliano Ramos. Livro: Vidas secas. Aula 3: Aula na Pinacoteca. Obras de Almeida Júnior e modernistas.

Aula 4: A crônica e o conto. Autores: Stanislaw Ponte Preta, Affonso Romano de Sant'Anna, Machado de Assis, Clarice Lispector e Carlos Drummond de Andrade. Livros: O melhor de Stanislaw Ponte Preta, Porta do colégio e outras crônicas, Os melhores contos de Machado de Assis, Outros escritos, O primeiro beijo e outros contos e Os dias lindos.

Aula 5: A literatura indigenista ontem e hoje: José de Alencar e Milton Hatoum. Livros: Iracema e Órfãos do Eldorado.

Aula 6: Prosa ou poesia? Autora: Cora Coralina. Livros: O tesouro da casa velha e Poemas dos becos de Goiás.

Aula 7: Poesia brasileira e poesia paulista: Manuel de Barros, Mário Quintana, Adélia Prado, Arnaldo Antunes e demais poetas paulistas da compilação Paixão por São Paulo (Org. Luiz Roberto Guedes).

Aula 8: Autoras contemporâneas: Noemi Jaffe e Carol Bensimon. Livros: O que os cegos estão sonhando? e Todos nós adorávamos caubóis.

Aula 9: Quando a literatura brasileira se torna best-seller internacional: o caso Paulo Coelho. Livros: Brida e O Alquimista.

Aula 10: Quando a literatura internacional entra no Brasil: poemas de Amarjit Chandan, Bejan Matur e Sujata Bhatt traduzidos para o português brasileiro por Ana Amália Alves. 


\title{
NOTES ON A BRAZILIAN LITERATURE COURSE FOR FOREIGNERS IN BRAZIL
}

\begin{abstract}
In this article are some reflections on the creation of the course on Brazilian Literature for Foreigners and the conduction of the classes as a freelance teacher in a languages school in São Paulo from May to June 2015. This is a case study and an attempt to contribute to the newly established field of research on teaching Brazilian Literature for speakers of other languages in Brazil.
\end{abstract}

KEYWORDS: education; Brazilian literature, Brazilian Portuguese as a foreign language

recebido em: $31 / 10 / 2015$

Aprovado em: 04/02/2016 